\title{
Plasticity and Programming: Feminism and the Epigenetic Imaginary
}

\section{Citation}

Richardson, Sarah S. 2017. "Plasticity and Programming: Feminism and the Epigenetic Imaginary." Signs: Journal of Women in Culture and Society 43 (1) (September): 29-52. doi:10.1086/692446.

\section{Published Version}

doi:10.1086/692446

\section{Permanent link}

http://nrs.harvard.edu/urn-3:HUL.InstRepos:34945789

\section{Terms of Use}

This article was downloaded from Harvard University's DASH repository, and is made available under the terms and conditions applicable to Open Access Policy Articles, as set forth at http:// nrs.harvard.edu/urn-3:HUL.InstRepos:dash.current.terms-of-use\#OAP

\section{Share Your Story}

The Harvard community has made this article openly available.

Please share how this access benefits you. Submit a story.

Accessibility 
Forthcoming in Signs

\title{
Plasticity and Programming:
}

Feminism and the Epigenetic Imaginary

\author{
Sarah S. Richardson
}

\begin{abstract}
The new science of epigenetics has raised hopes of an embrace of greater plasticity and variation within the biology of sex, gender, and sexuality than previously appreciated. This essay describes and analyzes the integration of epigenetics research into the scientific study of core biological pathways related to sex, gender, and sexuality in the brain in the post-Human Genome Project era. Through a close reading of the primary scientific literature, it demonstrates that epigenetic approaches in this subfield remain continuous with historically well-entrenched models of hardwired brain sexual dimorphism. Considering the opportunities and dilemmas of feminist engagements with the fast-moving and still nascent field of epigenetics, it argues that while epigenetics might become a resource for studies of the development and plasticity of gendersexed bodies and identities, this will require active feminist contestations of the ontological and epistemological commitments of mainstream research in this field. Feminist attraction to the possibilities for epigenetic research to enable material investigation of gender embodiment and sexual variation follow a long tradition of feminist theoretical interest in plasticity-affirming biologies. Careful consideration of the case of epigenetics suggests a need for revised and more nuanced feminist appraisals of both plasticity-affirming and programming-centric models of biology, body, and sociality
\end{abstract}

The "living being does not simply perform a program," writes French feminist philosopher Catherine Malabou in a 2015 Critical Inquiry essay on the new science of epigenetics. Epigenetics, she argues, "unsettle[s] the equation between biological determination and political normalization." For feminists, the science of epigenetics holds a "power of resistance," offering political possibility through the "deconstruction of program, family, and identity," "fractur[ing] the presumed unity of the political subject." Similarly, in her 2014 "Politics Materialized: Rethinking the Materiality of 
Feminist Political Action Through Epigenetics," theorist Noela Davis proffers epigenetics as a resource for feminists working to "rethink matter, its vibrancy, dynamism and agency" (63). Feminist and queer theories that understand bodies as "performative processes of materialization rather than given or inert bases to be worked on by cultural activity" (65), she argues, may find empirical support in the new science of epigenetics.

Epigenetics is a new, methodologically diverse, controversial, and fast-moving scientific field attached to powerful progressive and reconstructive social and political imaginaries - that is, philosophies of life and materiality - at the intersections of the life and social sciences. Malabou and Davis exhort feminists to approach epigenetics as a grounding for feminist theory, suggesting that it might serve feminist theories of nonbinary, plastic and diversity-affirming conceptions of sex and gender. Cultivating biological data as a source with which to imagine feminist futures and produce alternative conditions of possibility for political action, feminist new materialists such as Malabou and Davis seek to break down the distinction between the political and material and to build feminist theory out of the blood, guts, brains, and epigenomes that makes up what they conceptualize as the very "materiality" of scientific investigations. The 'thinking with' the wetware of biology that new materialist theorists seek to cultivate, however, raises worries of a decontextualized approach to the posits of biology and an uncritical embrace of a material grounding for political action. The case of epigenetics makes this particularly clear.

Contributing to the empirical history and social studies of science literature on the heterogeneous transformations wrought by the science of epigenetics across the life 
sciences, the first part of this essay analyzes the entry of epigenetics into theories and modes of inquiry in research on sex differences in the mammalian brain and social behavior, a classically charged field of scientific study with deeply contested frameworks and a history of ideological deployments within wider social debates about male and female human nature (Fine 2010; Jordan-Young 2010). Attending to history and to local and situated practices in the epigenetics of sex in the brain significantly recasts the widely perceived relationship between epigenetics and plasticity-affirming biologies. As I demonstrate, in contrast to a broad reigning discourse associating epigenetics with biological plasticity in response to social and environmental context, in current research on sex differences in the mammalian brain, epigenetics serves a mechanism by which genes and hormones produce and maintain sexual dimorphism. Rather than complexifying, perturbing, or making less determinant and more variable sexual phenotypes, epigenetic factors, in this prevailing model, work to fix and direct dimorphic development by encoding binary patterns of gene expression in the brain.

The observation that epigenetics has, in practice, only replicated and amplified deterministic and binary models of the biology of sex differences in the brain and behavior, does not, of course, imply that feminists should abandon the plasticity- and diversity-affirming potentialities of epigenetics. But it does highlight the importance of careful and critical attention to the unfolding meanings of epigenetics research in context and practice before embracing epigenetics as a foundation for feminist theoretical and empirical claims. Taking up feminist provocations regarding the possibilities for epigenetics to inform feminist theory, the second part of this essay 
considers the opportunities and dilemmas of feminist engagements with the still nascent field of epigenetics. Intellectual exchange between epigenetics and feminist theory, I argue, cannot be based merely on a posture of fascination or on recognition of certain shared proclivities. Epigenetic science is contested and the political imaginaries attached to it are plural and complex. Hence, I argue for the importance of feminist empiricist approaches to epigenetic science, including: critical assessment of the strength of scientific claims relevant to the interaction of gender and epigenetic mechanisms; strategic challenges to the methods, concepts, and empirical findings of epigenetics research; and, submitting feminist intuitions - including those regarding the concept of 'plasticity' itself - to test.

\section{Plasticity and programming: epigenetics, sex, and the brain}

Epigenetics refers to molecular mechanisms that regulate DNA expression in response to genetic and non-genetic cues. Studies of epigenetic mechanisms arrived coincident with transformations in the life sciences in the aftermath of the completion of the major genome projects. Increasingly over the past decade, biomedical researchers have turned from the question of DNA sequence to that of DNA regulation. Common epigenetic mechanisms include methylation, acetylation, microRNAs, and histone modification, all of which function as molecular co-factors that repress or activate DNA. DNA microarray technology allowing researchers to easily assess the presence of epigenetic regulation in particular tissues and regions of the genome has 
facilitated the rapid movement of epigenetic research into nearly every field of the biomedical sciences.

Iconic epigenetic studies involve riveting claims of dramatic changes in epigenetic markings as a result of environmental exposures. Rat pups stimulated by maternal licking gain epigenetic markings at key loci involved in stress regulation to become low-anxiety adults (Szyf et al. 2005). Members of poorer classes in Glasgow, Scotland, exhibit lower global methylation levels than do the wealthy (McGuinness et al. 2012). A series of Scandinavian studies suggest that one's grandparents' experience of famine may be recorded in the epigenome, altering descendants' health even without changes to the DNA itself (Bygren, Kaati, Edvinsson 2001). Emphasizing the reactivity and responsiveness of the body to social and environmental influences, such findings make it seem plausible that epigenetics could offer a rich and provocative theoretical frame for understanding gender-sex at the level of the body.

In the spring of 2015, a new epigenetic study suggesting a thrilling and intellectually challenging rewriting of long held paradigms of profound and fixed differences in the biology of brain sex and gender appeared in the journal Nature Neuroscience. The study, "Brain feminization requires active repression of masculinization via DNA methylation" (Nugent et al. 2015) used the emerging toolkit of epigenetics to examine sexual differentiation in the preoptic area of the rat brain. A locus of great interest and contention among scholars of sex, gender, and the brain, the preoptic area (POA) is implicated in sex differences in rodent reproductive behavior and is claimed to be among the most sexually dimorphic regions of the mammalian brain. 
The study seemed to challenge received understandings of sex differences in the POA at several levels. In apparent contrast to a view of male and female brains as dimorphically organized and hardwired during early development, the study found that epigenetic mechanisms permitted the POA to be "highly modifiable," exhibiting "rapid" changes in levels of epigenetic markers in response to "changes in excitability" (Nugent et al. 2015,1$)$. Against the long-held view that the female condition is the passive default in the absence of masculinizing factors that repress feminization, the authors argued that epigenetic mechanisms reveal that "feminization is an active and ongoing repression of masculinization and thus reversible" (7). They concluded that this finding is "evidence for the duality of the brain, with some arguing for the simultaneous presence of both male and female circuits or phenotypes" (7). Finally, at odds with a history of overwhelming focus on documenting and quantifying sex differences in the brain, the authors positioned epigenetics as an overriding mechanism in the brain that can function to equalize levels of gene expression between males and females. While 70 genes showed sex differences, the other 381 - which they termed "convergence genes" - maintained equal levels of expression with the aid of epigenetic markers (6).

The study, from the laboratory of University of Maryland neuroendocrinologist Margaret McCarthy, could be read as suggesting the possibility for much greater dynamism and variability in sex and gender phenotype in the mammalian POA than has previously been appreciated. It hinted that epigenetics may reveal that differences once understood as hardwired are perhaps more accurately tripwired, held in place by delicate and contingent epigenetic processes subject to reversal. Such plasticity- 
affirming, gender-bending findings speak to the highest hopes of feminist scholars for the new science of epigenetics: that epigenetics may counter traditional ideological conceptions of male and female differences by documenting a diversity of sexual phenotypes; and that epigenetics may provide methods for studying biological embodiment of gender by yielding mechanisms for environmental and social mediation of sex.

Yet the authors themselves, and the scientific community, did not embrace this vision. In the scientific and public discussion that followed the publication of the study, scientists asserted that its findings represent further confirmation of the longstanding paradigm of hardwired and dimorphic sex differences in the brain. As the study's lead co-author, Bridget Nugent, said, "My hope is that these studies have taken us one step closer to fully understanding how and why males and females are so different" ("Sex on the Brain" 2015). A 2015 The Scientist article, titled "Female Brain Maintained by Methylation" (Azvolinsky 2015) framed the study as explaining how "differences in male and female rodent sexual behavior are programmed during brain development" and as offering further evidence of how "male hormones unleash the male program." The article asserted that "these latest findings suggest that there may be more sex differences in the rodent brain than previously thought." Leading sex differences researcher Georgia State University neuroendocrinologist Geert de Vries said of the study: "Our understanding that the female state of the brain is the default still stands. What changes now, because of this study, is our thinking as to how that default state is preserved" (Ibid). 
Close analysis of the dynamics of the integration of epigenetics research into recent basic biological studies of sex, gender, and sexuality illuminates why researchers see this study as corroboration for longstanding models of the brain's stringent maintenance of sexual dimorphism, and as a finding of new sex differences in the previously unexplored realm of epigenetic markings, rather than as a diversity- and plasticity-affirming conceptual framework for understanding the materiality of sex and gender. Very broadly, there are two explanatory projects in epigenetics-centric sciences. One examines how epigenetic mechanisms play an integral and generalized role in the unfolding of human development, mediating between hormones and genes to execute normal developmental processes such as growth, brain development, puberty and menopause, and aging. This is presently most recognizable as a research program in developmental genetics. Another looks at how, in response to environmental cues, discrete epigenetic mechanisms at particular sites on the genome can be "programmed" in a way that contributes causally to individual phenotypic outcomes, including those conceptualized as pathology, such as high anxiety or obesity. This work is currently most legible as is a research program at the intersection of environmental and genetic epidemiology.

These two projects - long-standing effects of early epigenetic programming and the short term or fleeting role of epigenetic mechanisms in the "plastic" mediation of environmental cues and gene expression throughout the life course - mirror and inform a long-established explanatory framework for approaching the biology of sex that makes room for developmental plasticity as well as stability. ${ }^{1}$ Originating at the turn of the 
twentieth century with the discovery of sex hormones and sex chromosomes, this explanatory framework posited a model of sex in which genes and chromosomes determined initial sexual fate and gonadal hormones such as estrogens and androgens determined sexual differentiation and secondary sexual traits (Richardson 2013). Hormones, the twentieth century avatars of sexual plasticity, function by conveying biochemical messages from cell to cell, leading to changes in gene expression and metabolic function. Mid-twentieth-century studies of sex hormones in relation to rodent sexual differentiation of the gonads and brain, and to sex differences in social behavior, led to the commanding activational-organizational explanatory framework for the biology of sex. According to this model, sex hormones such as androgens and estrogens have two causal repertoires. An organizing effect occurs during the development of an organism and irreversibly primes or programs tissues to respond in certain set ways to later physiological events. Sexual differentiation of reproductive organs during early fetal life is an excellent example of this. An activating effect is one produced by circulating hormones in the mature organism. For instance, adrenalin increases heart rate, and estrogen levels release luteinizing hormone in women. ${ }^{2}$

In the twentieth century, researchers advanced a linear model of genetic and hormonal sex determination in which the presence of the $Y$ chromosome and testosterone masculinized a default female body plan during early development. Then, throughout the life course, sex hormones regulate genes to maintain sexual differentiation and sex-related functions. Epigenetic mechanisms today form a linchpin of an even more dynamic model in which hormones and genes interact throughout the 
life course to regulate sex-differentiating processes. Yet the received explanatory framework of organization and activation, and of programming and plasticity, persists.

Epigenetics first entered basic biological sex research at the turn of the twentyfirst century, during a paradigm shift in the life sciences from studies that assume a few determinant factors to more non-reductionist, "postgenomic" approaches that invite a wide repertoire of co-factors in biological explanations. ${ }^{3}$ In 2012, University of California, Los Angeles, geneticist and neuroscientist Arthur Arnold coined the term "sexome" to describe this postgenomic understanding of the biology of sex (Arnold and Lusis 2012). Arnold and colleagues describe the sexome as an interactive dynamic network comprised of many sex-biased factors, including epigenetic ones, involved in all life processes. The terminology of the systems sciences - complexity, pulsating networks, dynamic interactions, and emergence - pervades new epigenetics-centric models of the biology of sex:

[W]e envision the function of cells, tissues, and individuals to be controlled by complex intersecting causal pathways, in which specific physical events cause changes in other events. .... In this analogy, functional gene networks pulsate with activity, with specific nodes increasing and decreasing in their activity, stimulating and inhibiting each other, creating a dynamic net of interactions that lead to emergent phenotypes (such as heart rate, fat and energy metabolism, etc.). Sex differences in gene networks and in the phenotypes that they control, are created when the activity of some nodes is greater in one sex 
than in the other; the sex differences in network functions are caused by sexspecific factors acting in the network. The totality of sex-biased factors in the network comprise the sexome. (Arnold, Chen and Itoh 2012, 3)

Adherents contrast a "traditional" view of genetic and hormonal determination of brain sexual differentiation with their "modern" view, in which many co-factors, including epigenetic ones, orchestrate sex-specific processes throughout the brain:

This traditional view, seductive in its simplicity, must now be replaced. Sufficient new evidence has accumulated to warrant a shift away from the old serial model and toward a more complex and nuanced model in which numerous sex specific factors, hormonal, genetic and epigenetic, act in parallel to cause or eliminate sex differences in the brain and other tissues, by mechanisms that frequently are region specific and heterogeneous in terms of their intracellular mechanisms and mode of cell-to-cell communication. The modern view emphasizes a diversity of proximate mechanisms and an interaction of multiple sex-specific factors in many brain regions. (McCarthy and Arnold 2011, 1)

In this picture of sex in the brain, hormones, genes, and experiences play parallel and interacting roles to actively create and maintain sex differences. Epigenetic mechanisms comprise a key element of postgenomic models of the biology of sex. As visualized in 
Figure 1, in such a model long-lasting sex-specific epigenetic modifications in early mammalian brain development result in "sexually dimorphic epigenomes."

[INSERT FIGURE 1 HERE]

Over the past decade, epigenetic mechanisms have emerged as a prominent explanatory resource in the studies of the biology of sex and the brain, in two principal ways. First, epigenetics has provided a new toolkit for elucidating the molecular mechanisms of hormone-gene regulation. Take, for instance, the estrogen receptor $\alpha$ $(E R \alpha)$ gene, a major target of current research on the epigenetics of sociosexual behavior regulation in the brain. Changes in levels of expression of the ER $\alpha$ gene alter sensitivity to estrogen. A substantial line of present research examines how epigenetic mechanisms such as methylation and histone acetylation of the ER $\alpha$ gene varies between males and females, over developmental time, and in different regions of the brain. In mice, sex differences in methylation and histone acetylation at the ER $\alpha$ gene caused by exposure to the steroid estradiol have been observed in the preoptic area and mediobasal hypothalamus during early development. Altering exposure to estradiol during the prenatal period changes the rate of DNA methylation, in turn changing levels of ER $\alpha$ gene expression in males and females (Matsuda 2014). Another hormonal target of epigenetic investigation, oxytocin, is involved in lactation and also theorized as a central component of human social and emotional regulation and bonding. Oxytocin has sex-specific effects in males and females. Researchers are investigating how 
epigenetic mechanisms mediate sex differences in fetal and infant response to maternal stress or separation (Alves et al. 2015). Correlating early epigenetic programming with measures of oxytocin and variation in social behavior in adults, these studies position epigenetics as a link between early adversity, hormonal changes, and sex differences in adult behavioral phenotype.

Secondly, epigenetic mechanisms have supplied a new hypothetical mechanism to fill in causal "black boxes" in explanations of the biology of sex, gender, and sexuality in the brain and social behavior. In explanatory schema, the visual icon of a black box represents a hypothetical causal mechanism or mediator, with inner workings that may be obscure, controversial, or complex, connecting an input and an output (Latour 1987). Take, for example, black box epigenetic explanations of the timing of female puberty. Scientists believe that puberty is ultimately caused by changes in the gonadotropinreleasing hormone neurosecretory neurons located in the hypothalamus but lack a clear picture of how the body decides when to initiate puberty. Epigenetics is filling this explanatory gap. A 2013 Nature Neuroscience article (Lomniczi et al. 2013) demonstrating that modification of epigenetic mechanisms can advance or delay the timing of puberty, for instance, postulated epigenetics as a "biological regulatory system that meets [the] requirements" to explain "how inherited, permanent changes in DNA sequence can regulate gene expression dynamically while also imposing an encompassing level of coordination and transcriptional plasticity on the gene networks involved" (2). Acknowledging that puberty involves a "cellular network" and that "no isolated pathway or cellular subset is solely responsible for the neuroendocrine control 
of puberty," the researchers embrace epigenetics as an "encompassing" framework and generalized regulatory mechanism to bring coherence to a network-like phenomenon in sexual development.

Epigenetics has also supplied an evocative black box causal mechanism for theorizing the biological development of homosexuality. "[M]ore than a decade of molecular genetic studies have produced no consistent evidence for a major gene, or other genetic marker, contributing to male homosexuality" (354), write evolutionary biologist William Rice and colleagues in a 2012 paper in The Quarterly Review of Biology (Rice, Friberg, and Gavrilets, 2012). Epigenetics, they propose, adds "the missing component." Rice et al. hypothesize that "canalizing epimarks" (344) alter the sensitivity of the fetus to testosterone, causing homosexuality. The term "canalization," historically employed to describe the emergence of organization and fixed states from complex, plastic non-determinate systems in biology, is here applied to suggest one way in which the biological plasticity of epigenetics can serve as a mechanism for inducing redundant, overdetermining direction in biological development. As visualized in Figure 2 , the concept of canalizing epimarks is a crystalline example use of hypothetical epigenetic mechanism as a black box to realize a causal model of homosexuality as a simple deviation from standard models of dimorphic sexual development (Figure 2).

[INSERT FIGURE 2 HERE]

In 2015, Eric Vilain and Tuck Ngun of UCLA presented research (Ngun and Vilain 
2015; see also Ngun and Vilain 2014) at the American Society of Human Genetics seeking to validate Rice's model. Their as-yet-unpublished paper, which has since attracted serious empirical critiques calling into doubt the soundness of the study (Yong 2015), claimed to find epigenetic markers that accurately predict the homosexual twin in mixed-sexual orientation monozygotic twin-pairs 67 percent of the time. Still new and highly controversial, research seeking the mechanistic basis of sexual orientation in deviations in the epigenetic development of the sexed soma provides an example of how, rather than disrupting biological determinisms, the materiality and theoretical resources of epigenetics may just as easily expand scientists' ability to position traces of biological sexual difference in relation to social categories of normalcy and abnormalcy (see Fausto-Sterling 2000; Terry 1999).

In sum, while epigenetics-centric models of sex reformulate the "stuff" that makes up sex, they do not represent a radical break from the explanatory projects of the twentieth century sciences of sex. In current studies of epigenetic mechanisms in sex, gender, and sexuality in the mammalian brain and social behavior, studies focus on the elucidation of the local role of epigenetic mechanisms in organizational and activational effects of steroid hormones at particular genetic loci and hormone receptors. The epigenetic effects under investigation are at well-defined genetic loci implicated in sex differences, such as the estrogen and oxytocin receptors. In black box biology theorizing the development of sociosexual behavior, such as puberty or sexual orientation, epigenetics is presently principally an explanatory resource for describing the canalization and maintenance of sex differences. 
Researchers conceptualize epigenetic mechanisms such as histone acetylation and methylation as mechanisms for gene regulation, orchestrated by hormones to produce and maintain sex differences. That is, epigenetic mechanisms serve to canalize and fix sex differences mediated primarily by genes and hormones. For the geneticist, epigenetic mechanisms explain gene action. They explain how gene expression responds to environmental cues, including but not limited to sex hormones. For the endocrinologist interested in sex differences, epigenetic mechanisms are believed to explain how, in response to environmental cues, hormones permanently organize or actively mediate gene expression. The continuity between twentieth century research programs and twenty-first-century epigenetics-centric sciences of sex can be further seen in the persistence of the "programming" metaphor in epigenetic science. ${ }^{4}$ Hence a typical finding of a epigenetics-sex study in the literature of this field follows a template: a positive result is one that shows the organizing, determining, or programming effect of an epigenetic mechanism in establishing sex differences. "[T]estosterone acts via epigenetic processes, in particular the regulation of histone acetylation, to direct sexual differentiation of the brain," conclude McCarthy et al. $(2009,12819)$. "These findings suggest that environmental differences during development are programmed in the brain as a different pattern of epigenetic marks, and that this leads to differences in neuroendocrine and behavioral characteristics after maturity," writes Matsuda (2014, 4).

Appreciation of the explanatory role of epigenetic mechanisms within the present-day sciences of sex, gender, and sexuality in the brain yields three insights 
deeply discordant with feminist new materialist hopes for epigenetics. First, while researchers acknowledge the importance of environmental cues in epigenetic regulation, within the brain sex differences field epigenetics is not presently conceptualized as a source of ongoing plasticity in sex and gender itself. Rather, epigenetic mechanisms function as a powerful and overdetermining agent in the canalization and programming of sex differences - not despite, but because of, their plasticity. In current research on brain sex, gender, and sexuality, epigenetics is understood as a ubiquitous and flexible adaptive mechanism that reliably works in a dynamic, plastic manner to enforce binary sex-differentiated pathways within the body. Sex differences in epigenetic regulation stabilize and overdetermine binary sexual dimorphism in the brain. In this field, environmental cues are largely restricted to other molecular factors - hormonal and genetic - in the immediate biological milieu, not social and cultural context. These epigenetic mechanisms are typically themselves genetically determined - meaning that they are understood as biological agents, the existence and function of which is ultimately encoded in the DNA, and which are designed to be reliably deployed within the organism to maximize adaptive aims.

Second, epigenetic plasticity is understood as itself sexually dimorphic. Epigenetics inquiry is currently focused on epigenetics as a source for the elucidation of the biology of sex-specific responses to the environment, not on how environmental exposures create variation in sex-stereotyped behavior in males and females. Male and female epigenetic plasticity in response to the environment is itself theorized as sexually dimorphic. In much-celebrated epigenetic mechanisms linking social environment and 
brain and behavioral phenotype, such as the link between maternal-infant licking and grooming behavior and epigenetic programming of brain pathways implicated in stress and anxiety in rats, for instance, the epigenetic pathways differ depending on the sex of the infant, as dams lick and groom male offspring more than female ones (see Champagne 2013).

Third, epigenetics-centric research models render sex dimorphism ubiquitous in the molecular architecture of the body. Sex-biased epigenetic mechanisms are theorized to mediate sex-specific processes at the interface of sex steroids and the genome in early development and throughout the lifespan. Epigenetics research thus postulates sex as a much broader part of the substructure of gene-environment interrelations. In explanatory models in the biology of sex that invoke epigenetics, sex and gender become ubiquitous processes, not localized to gross regions of sexual dimorphism (see de Vries and Forger 2015). In the twentieth century linear model of sex, sex inhered only in sex-specific elements such as the $X X$ and $X Y$ chromosomal complements or reproductive organs such as the testis and ovaries. In postgenomic models, the whole body is imbued with networked processes that are sexed. Conceptualizing any process that involves genes or hormones as sexed, postgenomic and epigenetic-centric research programs greatly multiply the binary sites, signs, and signifiers of sex in the body. Rather than epigenetics and/or the environment becoming a resource to explain sexual variation, sex differences become an expanded explanatory resource for explaining biological variation. 
In these many ways, epigenetics, insofar as it is a plasticity-affirming biology, is not in any necessary way a kin to feminist imaginaries of the gender-plastic body. In this case, forms of biological plasticity walk in lockstep with programming and its affiliated determinisms and binaries. Plasticity is often associated with malleability and variation, and programming with hardwiring and permanence. But historically, these two concepts are polysemic, and need not be oppositional, or even mutually exclusive, within biological explanations of sex. Plasticity can be programmed, and programming can be plastic. Indeed, in the field of brain sex research, epigenetics inherits well-trod modes of operationalizing plasticity within the programming discourses of the hormonal and genetic life sciences. As such, the movement of epigenetics to the center of sex difference research in the brain currently appears as poised to reiterate, and even amplify, essentialist and thoroughgoing notions of biological sex differences, as to complicate or soften them.

\section{Feminism and the epigenetic imaginary: critical contestations and empiricist}

\section{approaches}

Feminist theorists and scientists who embrace wide-ranging human variation in sex, gender, and sexuality and reject essentialist and binary conceptions of human difference have long sought empirical and material methods for studying gendered embodiment to facilitate greater empirical understanding of the role of social and cultural context in shaping human bodies. Calling for a biology less focused on fixed differences, feminist historian and philosopher of science Evelyn Fox Keller, in her 2010 
The Mirage of a Space between Nature and Nurture, urges scientists to shift their central question from one of the extent of biological determination to one of "degree of phenotypic plasticity" (75). "[H]ow malleable is a given trait, at a specified developmental age?," she asks (Ibid.). Feminist scientists and science studies scholars have innovated theories and research methods to study the sexed and gendered plasticity of bodies and biologies. In her recent contributions to the study of the embodiment of gender-sex in early child development, for instance, biologist and feminist theorist Anne Fausto-Sterling (2012) employs dynamic systems theory to model and empirically study the iterative play of sex and gender in critical developmental transitions. Similarly, in her current research on testosterone, gender, and aggression, feminist social neuroendocrinologist Sari van Anders (2015) draws on gender theory to create novel experimental designs to study how gendered social interactions may alter hormonally mediated behavioral processes stereotypically linked to sex differences in modes of wielding power.

The question of how gender - the social norms and expectations associated with masculinity and femininity - is corporealized within the biological, sexed, body has been foundational to feminist theory since its inception. Fantasies of the plastic qualities of biological women under very different gender regimes animate iconic feminist texts. In her 1898 treatise Women and Economics: A Study of the Economic Relation Between Men and Women as a Factor in Social Evolution, Charlotte Perkins Gilman famously argued that the social conditions of subjugation had created "rudimentary female creatures" (164), weak in body and servile in mind. Gilman contended that sexual 
inequality between the sexes was produced and maintained by social factors working in interaction with the body and biology. With greater equality, she predicted that women would grow physically larger, stronger, and more agile (73-74). Three quarters of a century later, Joanna Russ's feminist science fiction classic The Female Man (1975) presented a proto-epigenetic parable, imagining a meeting between four women with identical genomes but from different time periods:

Look in each other's faces. What you see is essentially the same genotype, modified by age, by circumstances, by education, by diet, by learning, by God knows what. Here is Jeannine, the youngest of us all with her smooth face: tall, thin, sedentary, round-shouldered, a long-limbed body made of clay and putty; she's always tired and probably has trouble waking up in the morning. $\mathrm{Hm}$ ? And there's Joanna, somewhat older, much more active, with a different gait, different mannerisms, quick and jerky, not depressed, sits with her spine like a ruler. Who'd think it was the same woman? There's Janet, hardier than the two of you put together, with her sun-bleached hair and her muscles; she's spent her life outdoors, a Swedish hiker and a farmhand. You begin to see? [...] We ought to think alike and feel alike and act alike, but of course we don't. So plastic is humankind! (163-165, my emphasis)

In The Female Man, differently gendered social and cultural contexts produce striking variation in embodied sex and gender comportment. Most recently, the BBC/America 
science fiction series "Orphan Black" (2013-) praised for its scientific acumen and feminist vibe, features a single actress who plays different versions of contemporary women - and a transgender man - with identical genomes. The television show is a gender-bending phantasmagoria, showing the clones living wildly divergent lives: timid braniac and lesbian Cosima; uptight, straightlaced soccer mom Alison; the transgender character Tony; and, needy, mentally deranged Helena, among others. The diversity of Western gender performativity - at once embodied and firmly delinked from genomic endowment - is on impressive display. The show's writers regularly invoke epigenetics as an explanation for this rainbow of characters, as in one episode in which the female child character, Kira, is teasingly advised not to eat too much "salted fish" or she will "end up with a beard": "It's epigenetics, monkey. It's a proven fact" (Orphan Black 2015). These compelling visions of gender plasticity form an imaginary that has historically animated feminist intrigue with plasticity-affirming biological theories of all sorts, including epigenetics.

For feminist theorists, then, epigenetics is not only a set of scientific propositions, data, methods, and practices. It is also a discursive imaginary advancing heterogeneous future-oriented visions. This is true not only within feminist discourse, but in a variety of other arenas within and beyond the life sciences. This imaginary is visually represented by the increasing displacement of the trope of the genetic age, the double helix, by a new iconography of diagrammatic spaces showing genomes, human bodies, and physical and social environments in dynamic interaction over time and space. Epigenetics in these renderings is not a mere mechanism - a methyl group 
nestled against a double helix, say - but an arrow within often messy and variegated causal spaces. Epigenetics connects history and future, mother's exposures and child's outcomes, social policy and individual bodies. In these explanatory schemas, epigenetics is not reducible to any particular molecular mechanism: it is a theoretical causal resource in a much more expansive and theoretical sense. Over the past decade, epigenetics has entered several streams of scholarly and public intellectual discourse beyond the sciences, from Deepak Chopra's New Age pronouncements that with meditation and good nutrition "you can change your genes," to clickbait headlines such as "Why you should be worried about your grandmother's eating habits" (Chopra 2015; Rank Lev 2014).

Within the academy, social scientists see epigenetics as a potential tool for the empirical study of biosocial interactions and as a corrective to the bald determinisms they perceived in the genetic era. A 2013 Annual Review of Sociology essay by Hannah Landecker and Aaron Panofsky situates epigenetics as representative of a "renegotiation and reconfiguring of the biological, the social, and their interrelation" (353) in the postgenomic moment. They describe epigenetics as "connecting social regulation to gene regulation in new and newly direct causal ways" (335), opening a "ccritical window" for engagement" (337) between the social sciences and biology. More broadly, they suggest that epigenetics offers a generative new "heuristic" for sociological theory. As they write, "the logic, temporality, and findings of epigenetics could be productively incorporated into both research and theory in sociology without requiring sociologists to learn how to do molecular biology. It can be a mode of 
thought, a form of attention, or a resource with which to build hypotheses and models" (346).

Yet the emerging science studies literature also reveals contestations over the political and social implications of epigenetics (Landecker and Panofsky 2013; Lock 2014). Science studies and bioethics scholars raise concerns about the possibility that epigenetics contributes to renewals of dangerous and stigmatizing forms of somatic determinism (Waggoner and Uller 2015). The notion that early social context can mark the body, programming it for life, presents a specter of biologically lesioned disadvantaged populations that may intersect in damaging ways with class- and racebased stigma (Mansfield 2012). The special role of the pregnant and reproductive-aged woman as a vector for intergenerational epigenetic programming raises worries of enhanced mother-blaming discourses accompanied by increased surveillance and regulation of maternal bodies (Richardson et al. 2014; Richardson 2015). Discourses of epigenetic plasticity encourage individuals to see themselves as protectors and cultivators of their own epigenetic health, inviting neoliberal discourses of health optimization as individual responsibility. ${ }^{5}$

Epigenetics is also a nascent and unsettled science accompanied by intense contestations within the life sciences over the validity of epigenetics findings and conceptual frameworks. ${ }^{6}$ Leading scientists express concerns that epigenetics is overhyped and charge that methodological issues cloud its central empirical claims. Only a brief summary of these issues is possible here. Most findings of correlations between human phenotypes and epigenetic patterns are difficult to interpret. 
Epigenetic marks may be a cause of the phenotype; they may also be a result of it. Epigenetic mechanisms, particularly in the broadest sense of the term - as the apparatus of gene regulation - are now presumed to be relevant to any biological process. But omnirelevance must not be mistaken for power or precision in the mechanism itself. Changes in the epigenome (or the set of epigenetic markers at any region of interest in the genome) indicate system-level changes. These changes may be of potentially high biological import, or they may be part of regulatory systems so complex and redundant that any one change cannot be clearly read as correlated or causally linked to any particular event. The effect sizes of epigenetic perturbations are extremely small and often hard to detect and replicate (Francis 2014). Epigenetic studies overwhelmingly focus on methylation, but methylation and other singular epigenetic factors interact with many other cofactors that are presently poorly understood.

There are further limitations when considering humans in particular. The visually dramatic effects of epigenetic markers in the cases of meta epi-alleles, such as the mouse agouti locus, where changes in methylation in the maternal diet can grossly alter the hair color and body size of offspring, have not been apprehended in humans. Indeed, in humans, what constitutes a "normal" or "abnormal" epigenome is still not fully intelligible (Greally 2015). Similarly, whether epigenetic marks acquired in early life are truly permanent in humans is not well understood. Despite the popular fascination with claims of transgenerational epigenetic inheritance, to date, there are only a few 
uncontested examples of truly transgenerational epigenetic inheritance, and these are in non-human organisms, mostly plants (Heard and Martienssen 2014).

The case of epigenetics in the sciences of mammalian brain and behavioral sex differences adds to this picture of epigenetics as an emergent science accompanied by plural biosocial imaginaries and empirical and conceptual contestation. While some invoke epigenetics as a grounding for plasticity-affirming feminist theories, fine-grained analysis of epigenetics approaches as they are deployed within the on-the-ground language, claims, and cognitive and social practice of this particular area of present-day science yields a different imaginative horizon. In this field, epigenetics adds a new mechanism to biological explanations of sex that have long accepted a complementary repertoire of deterministic, programmed biological processes and dynamic, plastic biological systems. Indeed, on close inspection, epigenetic approaches appear continuous with historically well-entrenched models of hardwired brain sexual dimorphism.

None of this, of course, renders the prospect that epigenetics might in the future become a resource for studies of the development of gender-sexed bodies and identities informed by feminist theory impossible. But, it does suggest that such an aim will not emerge organically from the material facts of the science. Instead, it will require active feminist contestations of the ontological and epistemological commitments of mainstream research in this field. Feminist empiricist approaches that formulate new questions and analyze pretheoretical conceptual commitments within research are 
needed to explore the full potential of epigenetics for feminist theories of the body and biology.

In principle, epigenetics offers experimentally manipulable mechanisms for the study of the interaction of social context and biology. Hence, it offers plausible empirical and conceptual resources for feminist scientists and theorists of gendered bodies and biology. By asking different questions of the data and methods of epigenetics, feminist empiricist approaches might explore an alternative picture of the postgenomic biology of sex and contribute to the reorientation of the field. Feminist theory might inspire questions such as: How might epigenetic mechanisms interact continuously with genetic and hormonal factors rather than fixing sex differences at an early stage of development? What happens when social and broader environmental factors are included alongside hormonal and genetic ones as potential co-factors in the epigenetic apparatus of sex? Rather than hypothetical flowcharts ending in male and female epigenomes (Figure 1) might scientists consider models that include multiple canalizing trajectories, leading to, as Anne Fausto-Sterling (1993) once famously wondered, five genders/sexes rather than two ${ }^{7}$

Presently, we cannot claim that epigenetics affirms feminist theories of the plasticity of gender/sex. The plausibility that epigenetics might, as new materialist theorist Elizabeth Wilson urges, help feminists "build conceptual schemata about the body that are astute both politically and biologically" $(2004,86)$, however, is undeniably latent in the current epigenetics-sex literature. Consider, for instance, the productive and intriguing model for imagining engagements between the materiality of epigenetic 
mechanisms and feminist theories of the body and biology offered by studies of the methylation status of the previously discussed ER $\alpha$ gene. In rodents, the level of methylation at ER $\alpha$ in the sex-differentiated preoptic area of the brain varies over developmental time in relation to exposures to social and environmental factors. A female that has experienced simulated maternal grooming as an infant yields higher ER $\alpha$ methylation levels than one that has not. An adult female that resided, in the womb, between two female littermates exhibits higher methylation at that $E R \alpha$ receptor than one that grew between two males (Matsuda 2014). Such findings suggest the possibility of exploring the epigenetics of mammalian sexual variation in relation to life history over time by creatively proliferating the social and environmental exposures, genes involved, and regions of the brain and body of interest to experimentally assess the plasticity of sexed and gendered phenotypes.

Whether the potentiality of expansive sex and gender plasticity will be fully empirically explored in epigenetics research, however, will likely not be determined only by the "material" facts of the science itself. To develop epigenetics as a resource for feminist reconstructions of scientific models of the biology sex and gender, feminist science scholars must examine the larger causal-mechanistic claims and discursive and political imaginaries in which epigenetics research is embedded in practice. While scientific observations constrain the extent and range of possible biological plasticities at sex-related epigenetic loci, the direction of research and its theoretical extension within gender studies will substantially depend upon strategic contestations in the 
politics of gender and science around which questions are asked, which methodologies are adequate to ask them, and how gender-sex is conceptualized.

These sorts of contestations might revise and contribute to our understandings of how the "scene" (Wilson 2004) of socially mediated gender plays out in the body. But equally, the outcome may be that feminist theorists learn that plasticity, multifactoriality, complexification, and the contingency of determinants of sex/gender/sexuality is a less useful conceptual toolkit than it is often imagined to be. Indeed, the case of epigenetics suggests a need for revised and more nuanced feminist appraisals of both plasticity-affirming and programming-centric models in biology. Perhaps plasticity-affirming biologies do not produce a rainbow but a picture of the overdetermination of sexual binaries in the body. Testing these intuitions might provide impetus for deepening and reframing feminist investment in plasticity-affirming conceptual frameworks and aversion to programming-centric ones - and even for retheorizing the distinction between plasticity and programming altogether.

\section{Conclusion}

Answering what Margaret Lock (2013) has called "the lure of the epigenome" from the perspective of feminist science studies, this essay analyzes the integration of epigenetics research into the subfield of scientific study of the core biological pathways related to sex, gender, and sexuality in the brain in the post-Human Genome Project era. Today, epigenetics is an expanding explanatory resource in the basic biology of brain and behavioral sex. In coming years, researchers will almost certainly find 
epigenetic mechanisms correlated with many hormonal and developmental processes and they will find sex differences in those epigenetic processes themselves.

While epigenetics researchers embrace the importance of environmental inputs in biological systems, this does not lead them to affirmations of diversity and variation in sex and gender. For many epigenetics-sex claims, epigenetics functions as a redundant or overdetermining mechanism carrying out and maintaining the persistence of classic well established hormonal processes implicated in sex differences. ${ }^{8}$ Though a substantial conceptual divide persists between feminist theories of gender plasticity and dominant models of the epigenetic canalization of sexual dimorphism in the brain, future research programs to test hypotheses related to the plasticity of gender/sex may blossom. Thus far, however, the embrace of epigenetic mechanisms has not entailed the acceptance of greater plasticity and variation in sex and gender amongst scientific researchers. Instead, epigenetic research has more often reinforced and extended deterministic and binary conceptions of sex differences in brain and behavior, sustaining the "difference paradigm" of biomedical research on sex and gender robustly established in the twentieth century (Fausto-Sterling 2000; Epstein 2007; Richardson 2013).

Making sense of the striking divergence between feminist imaginaries and scientific researchers' appraisals of the conceptual potentialities perceived in epigenetics-sex findings requires appreciating the situatedness of plasticity-affirming biologies within a history of twentieth and twenty-first century sciences of sex deeply committed to a reigning metaphor of programming and to reductionist and determinist 
explanations. The case of epigenetics and brain sex difference research, furthermore, evidences the importance of attending to field-based specificities as science studies scholars map transformations in theory and practice introduced by the new science of epigenetics. In each scientific field, the explanatory reach of epigenetics emerges temporally through local practice and contestation and against the backdrop of received intellectual frameworks. Epigenetics is not only a material mechanism, but also a fluid imaginary functioning diversely across heterogeneous social spheres. Plasticity and programming are not necessarily opposites, but often two sides of the same coin. As new plasticity-affirming biologies arise, their materialities will not speak for themselves; feminist science scholars are called to critically and empirically contest the discursive, ontological, empirical, and methodological terms of epigenetic science itself. 


\section{Figure Captions}
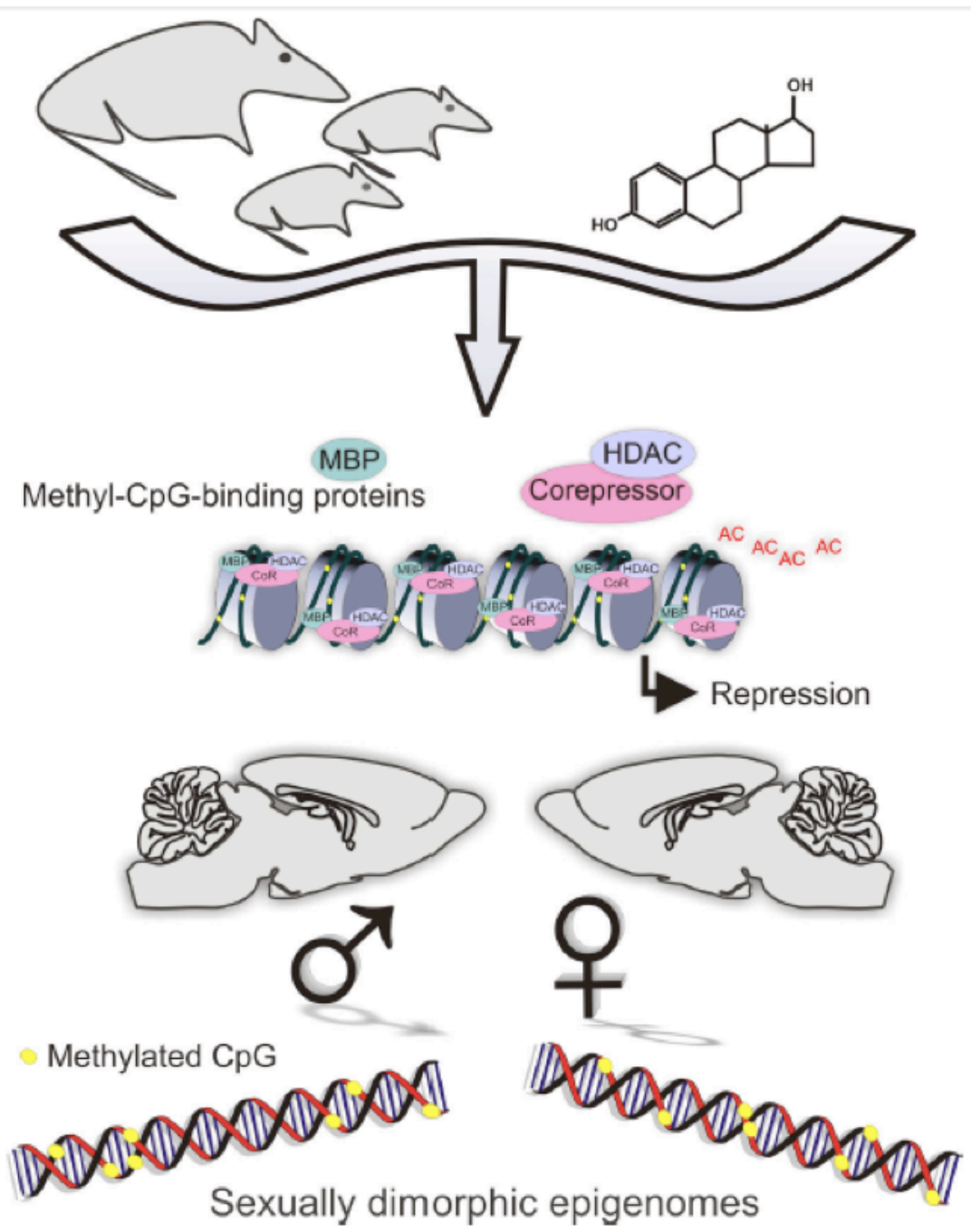

Figure 1

Sexually dimorphic epigenomes. "Emerging evidence suggests sex differences in at least four related parameters: (1) DNA methylation patterns, (2) methyl transferases, (3) methyl-binding proteins, and (4) corepressor proteins, all of which can contribute to lasting differences in the brain and behavior" (McCarthy et al. 2009, Figure 1). 


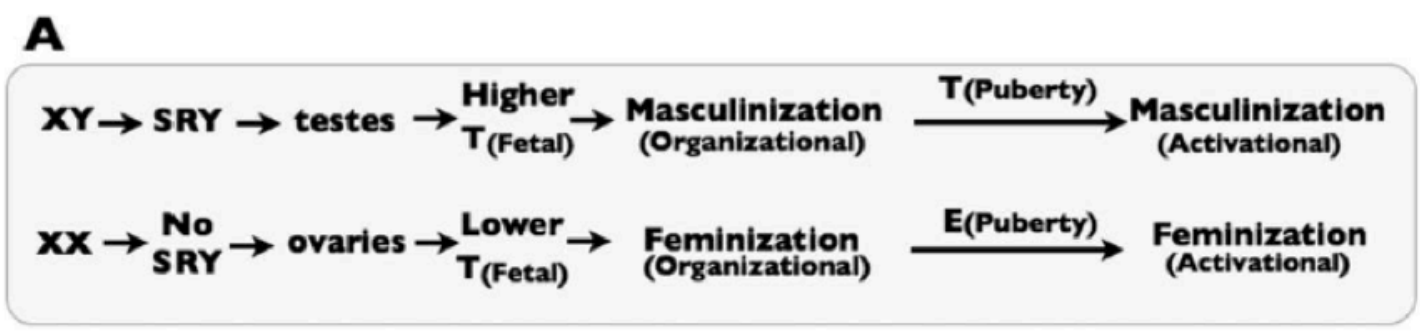

\section{B}

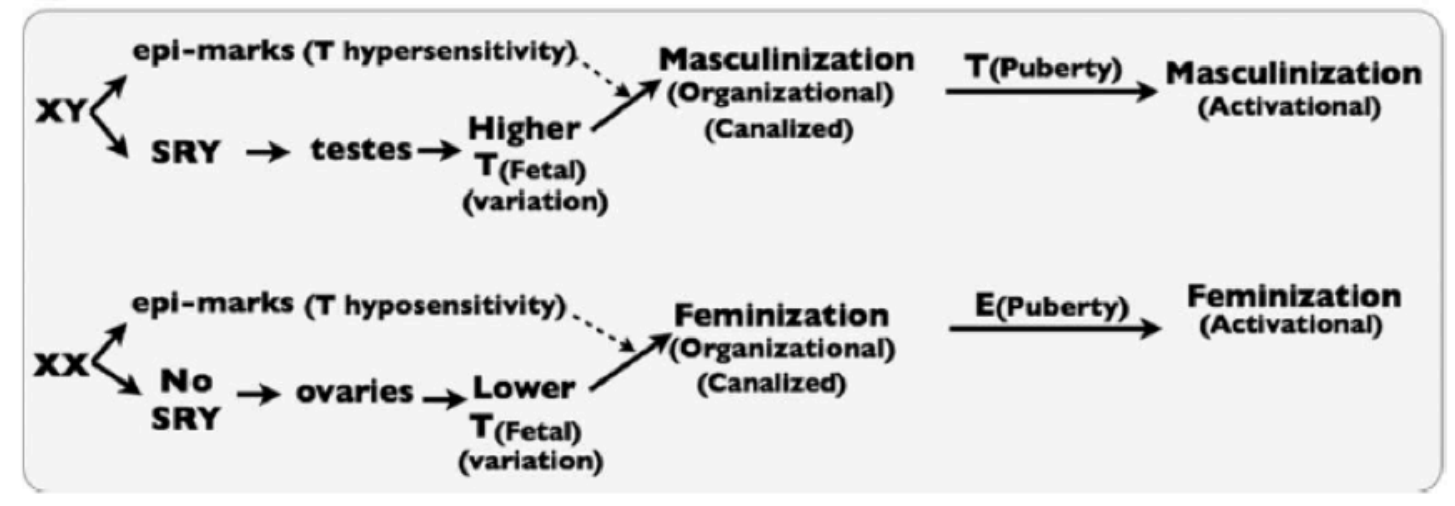

Figure 2

An epigenetic theory of homosexuality. "The classical view of sexually dimorphic development $(\mathrm{A})$ is that higher androgen levels in XY fetuses and adults masculinize sexually dimorphic traits and lower androgen levels in XX fetuses and high estrogen in adults feminizes development. Our analysis (B) indicates that androgen signaling includes an additional component: it is canalized by epi-marks that are produced during the embryonic stem cell stage of development" (Rice et al. 2012, Figure 1). 


\section{References}

Alves, Emily, Andrea Fielder, Nerelle Ghabriel, Michael Sawyer, and Femke T.A.

Buisman-Pijlman. 2015. "Early Social Environment Affects the Endogenous Oxytocin System: A Review and Future Directions." Frontiers in Endocrinology $6: 32$

Arnold, Arthur P., and Aldons J. Lusis. 2012. "Understanding the Sexome: Measuring and Reporting Sex Differences in Gene Systems." Endocrinology 153 (6): 2551-55.

Arnold, Arthur P., Xuqi Chen, and Yuichiro Itoh. 2012. "What a difference an X or Y Makes: Sex Chromosomes, Gene Dose, and Epigenetics in Sexual Differentiation." Handbook of Experimental Pharmacology 214: 67-88.

Azvolinsky, Anna. 2015. "Female Brain Maintained by Methylation." The Scientist, March 30. http://www.the-scientist.com/?articles.view/articleNo/42555/title/FemaleBrain-Maintained-by-Methylation/.

Bygren, Lars Olov, Gunnar Kaati, and Sören Edvinsson. 2001. "Longevity Determined by Paternal Ancestors' Nutrition During their Slow Growth Period." Acta Biotheoretica 49(1): 53-59.

Champagne, Frances A. 2013. "Effects of Stress Across Generations: Why Sex Matters." Biological Psychiatry 73(1): 2-4.

Chopra, Deepak. 2015. "Super Genes: The Key to Health and Wellbeing." Lecture, Boston, MA, December 1.

Davis, Noela. 2014. "Politics Materialized: Rethinking the Materiality of Feminist Political Action through Epigenetics." Women: A Cultural Review 25(1): 62-77. 
de Vries, Geert J., and Nancy G. Forger. 2015. "Sex Differences in the Brain: A Whole Body Perspective." Biology of Sex Differences 6:15.

Epstein, Steven. 2007. Inclusion: The Politics of Difference in Medical Research. Chicago: University of Chicago Press.

Fausto-Sterling, Anne. 1993. "The Five Sexes. " The Sciences 33(2):20-24.

--- 2000. Sexing the Body: Gender Politics and the Construction of Sexuality. New York, NY: Basic Books.

Fausto-Sterling, Anne, Cynthia Garcia Coll, and Meaghan Lamarre. 2012. "Sexing the Baby: Part 2 Applying Dynamic Systems Theory to the Emergences of Sex-Related Differences in Infants and Toddlers." Social Science and Medicine 74(11): 16931702.

Fine, Cordelia. 2010. Delusions of Gender: How our Minds, Society, and Neurosexism Create Difference. New York, NY: W. W. Norton.

Francis, Gregory. 2014. "Too Much Success for Recent Groundbreaking Epigenetic Experiments." Genetics 198(2): 449-51.

Gilman, Charlotte Perkins. (1898) 1970. Women and Economics. New York: Source Book Press.

Godfrey-Smith, Peter. 2000. "On the Theoretical Role of "Genetic Coding"." Philosophy of Science 67(1): 26-44.

Greally, John. 2015. "Human Disease Epigenomics 2.0." PLOS Biologue, July 7. http://blogs.plos.org/biologue/2015/07/07/human-disease-epigenomics-2-0/. 
Heard, Edith, and Robert A. Martienssen. 2014. "Transgenerational Epigenetic Inheritance: Myths and Mechanisms." Cell 157(1): 95-109.

Joel, Daphna. 2012. "Genetic-Gonadal-Genitals Sex (3G-sex) and the Misconception of Brain and Gender, or, Why 3G-males and 3G-females Have Intersex Brain and Intersex Gender." Biology of Sex Differences 3:27.

Jordan-Young, Rebecca M. 2010. BrainStorm: The Flaws in the Science of Sex Differences. Cambridge, MA: Harvard University Press.

Kay, Lily E. 2000. Who Wrote the Book of Life? : A History of the Genetic Code, Writing Science. Stanford, CA: Stanford University Press.

Keller, Evelyn Fox. 2000. The Century of the Gene. Cambridge, MA: Harvard University Press.

Keller, Evelyn Fox. 2010. The Mirage of a Space Between Nature and Nurture. Durham, NC: Duke University Press.

Landecker, Hannah. 2014. "Pregnancy: Study the Mother's DNA As Well." Nature 513(7517): 172.

Landecker, Hannah, and Aaron Panofsky. 2013. "From Social Structure to Gene Regulation, and Back: A Critical Introduction to Environmental Epigenetics for Sociology." Annual Review of Sociology 39(1): 333-57.

Latour, Bruno. 1987. Science in Action: How to Follow Scientists and Engineers through Society. Cambridge, Mass.: Harvard University Press. 
Lev, Katy Rank. 2014. "Why You Should Worry About Grandma's Eating Habits." Mother Nature News, April 21. http://www.mnn.com/health/fitness-wellbeing/stories/why-you-should-worry-about-grandmas-eating-habits.

Lock, Margaret. 2013. "The Lure of the Epigenome." The Lancet 381(9881):1896-97.

--- 2014. "Comprehending the Body in the Era of the Epigenome." Current Anthropology 56(2): 151-177.

Lomniczi, Alejandro, Alberto Loche, Juan Manuel Castellano, Oline Ronnekleiv, Martha Bosch, Gabi Kaidar, J. Gabriel Knoll, Hollis Wright, Gerd P. Pfeifer, and Sergio R. Ojeda. 2013. "Epigenetic Control of Female Puberty." Nature Neuroscience 16(3): 281-89.

Malabou, Catherine. 2015. "One Life Only: Biological Resistance, Political Resistance." Critical Inquiry, October 20. Translated by Carolyn Shread http://criticalinquiry.uchicago.edu/one_life_only/.

Mansfield, Becky. 2012. "Race and the New Epigenetic Biopolitics of Environmental Health." BioSocieties 7(4): 352-72.

Matsuda, Ken Ichi. 2014. "Epigenetic Changes in the Estrogen Receptor $\alpha$ Gene Promoter: Implications in Sociosexual Behaviors." Frontiers in Neuroscience 8: 344.

McCarthy, Margaret M., Anthony P. Auger, Tracy L. Bale, Geert J. de Vries, Gregory A. Dunn, Nancy G. Forger, Elaine K. Murray, Bridget M. Nugent, Jaclyn M. Schwarz, and Melinda E. Wilson. 2009. "The Epigenetics of Sex Differences in the Brain." The Journal of Neuroscience 29(41): 12815-23. 
McCarthy, Margaret M, and Arthur P. Arnold. 2011."Reframing Sexual Differentiation of the Brain." Nature Neuroscience 14(6): 677-83.

McGuinness, Dagmara, Liane M. McGlynn, Paul C.D. Johnson, Alan Maclntyre, G. David Batty, Harry Burns, Jonathan Cavanagh, Kevin A. Deans, Ian Ford, Alex McConnachie, Agnes McGinty, Jennifer S. McLean, Keith Miller, Chris J. Packard, Naveed A. Sattar, Carol Tannahill, Yoga N. Velupillai, and Paul G. Shiels. 2012. "Socio-Economic Status is Associated with Epigenetic Differences in the pSoBid Cohort." International Journal of Epidemiology 41(1):151-60.

Ngun, Tuck C., and Eric Vilain. 2014. "The Biological Basis of Human Sexual Orientation: Is There a Role for Epigenetics?" Advances in Genetics 86:167-84.

--- 2015. “Abstract: A Novel Predictive Model of Sexual Orientation Using Epigenetic Markers." Paper presented at the American Society of Human Genetics Annual Meeting, Baltimore, October 8.

Nugent, Bridget M., Christopher L. Wright, Amol C. Shetty, Georgia E. Hodes, Kathryn M. Lenz, Anup Mahurkar, Scott J. Russo, Scott E. Devine, and Margaret M. McCarthy. 2015. "Brain Feminization Requires Active Repression of Masculinization via DNA Methylation." Nature Neuroscience 18:690-97.

Orphan Black. 2013-. Directed by John Fawcett. BBC America. http://www.bbcamerica.com/shows/orphan-black/about.

--- 2015. “Certain Agony of the Battlefield." BBC America video, 46:21. May 23. http://www.bbcamerica.com/shows/orphan-black/season-3/episode-06-certainagony-of-the-battlefield. 
Pickersgill, Martyn. "Epistemic Modesty, Ostentatiousness and the Uncertainties of Epigenetics: On the Knowledge Machinery of (Social) Science." Sociological Review (Forthcoming).

Pitts-Taylor, Victoria. 2010. "The Plastic Brain: Neoliberalism and the Neuronal Self." Health 14(6): 635-652.

Rice, William R., Urban Friberg, and Sergey Gavrilets. 2012. "Homosexuality as a Consequence of Epigenetically Canalized Sexual Development." The Quarterly Review of Biology 87(4): 343-368.

Richardson, Sarah S. 2013. Sex Itself: The Search for Male and Female in the Human Genome. Chicago: University of Chicago Press.

---. 2015. "Maternal Bodies in the Postgenomic Order: Gender and the Explanatory Landscape of Epigenetics." In Postgenomics: Perspectives on Biology After the Genome, eds. Sarah S. Richardson and Hallam Stevens, Durham, NC: Duke University Press, 210-231.

Richardson, Sarah S., Cynthia R. Daniels, Matthew W. Gillman, Janet Golden, Rebecca Kukla, Christopher Kuzawa, and Janet Rich-Edwards. 2014. "Don't Blame the Mothers." Nature 512: 131-132.

Richardson, Sarah S., and Hallam Stevens, eds. 2015. Postgenomics: Perspectives on Biology after the Genome. Durham, NC: Duke University Press.

Russ, Joanna. 1975. The Female Man. Boston, MA: Beacon Press. Saluz, Hans Peter, Josef Jiricny, and Jean Pierre Jost. 1986. “Genomic Sequencing Reveals a Positive Correlation Between the Kinetics of Strand-specific DNA 
Demethylation of the Overlapping Estradiol/glucocorticoid-receptor Binding Sites and the Rate of Avian Vitellogenin mRNA Synthesis." Proceedings of the National Academy of Sciences 83(19): 7167-71.

Epigenie. 2015. "Sex on the Brain: DNA Methylation Defines Gender." March 31. http://epigenie.com/sex-on-the-brain-dna-methylation-defines-gender/.

Szyf, Moshe, Ian C. G. Weaver, Frances A. Champagne, Josie Diorio, and Michael J. Meaney. 2005. "Maternal Programming of Steroid Receptor Expression and Phenotype through DNA Methylation in the Rat." Frontiers in Neuroendocrinology 26(3-4): 139-162.

Terry, Jennifer. 1999. An American obsession: science, medicine, and homosexuality in modern society. Chicago: University of Chicago Press.

Towlinski, Kasia. 2013. "A New Genetics or an Epiphenomenon? Variations In the Discourse of Epigenetics Researchers." New Genetics and Society 32(4): 366-84.

Van Anders, Sari M., Jeffrey Steiger, and Katherine L. Goldey. 2015. "Effects of Gendered Behavior on Testosterone in Women and Men." Proceedings of the National Academy of Sciences 112(45): 13805-10.

Waggoner, Miranda R., and Tobias Uller. 2015. "Epigenetic Determinism in Science and Society." New Genetics and Society 34(2): 177-195.

Wilson, Elizabeth A. 2004. "Gut Feminism." Differences: A Journal of Feminist Cultural Studies 15(3): 66-94. 
Yong, Ed. 2015. "No, Scientists Have Not Found the 'Gay Gene'." The Atlantic October 10. http://www.theatlantic.com/science/archive/2015/10/no-scientists-havenot-found-the-gay-gene/410059/. 
Notes

${ }^{1}$ The alignment of the explanatory project of epigenetics with the organizational/activational model has its historical origins in the emergence of molecular epigenetics at the interstices between endocrinology and genetics. Studies of gene expression in relation to sex hormones played an important and proximate role in the conceptual origins of studies of epigenetic mechanisms such as methylation in the 1980s. An early example is Saluz et al. 1986.

${ }^{2}$ While the relevance of the activational-organizational model for understanding the sexual differentiation of the human reproductive organs is well established, its application to human gender and sexuality in the brain remains critically contested (Jordan-Young 2010, Joel 2012).

${ }^{3}$ On "postgenomics," see Richardson and Stevens 2015.

${ }^{4}$ A carry-over from informatics discourse pervasive in twentieth century genetics, the programming metaphor has been widely and critically dissected in science studies literature on genomics. See Kay 2000; Fox Keller 2000; Godfrey-Smith 2000.

${ }^{5}$ For a development of this argument in the case of neuroplasticity discourse, see PittsTaylor 2010.

${ }^{6}$ Science studies scholars have documented extensive contestations among scientists about the validity of epigenetics findings and the revolutionary nature of epigenetics with respect to genetics. See Towlinski 2013; Pickersgill Forthcoming.

${ }^{7}$ Landecker (2014), for example, points out that while there have been voluminous studies of the effects of maternal behavior on the fetal epigenome, scientists have not 
examined the epigenetic changes induced in women by pregnancy. A research program examining the epigenetics of women's diverse reproductive histories might yield empirical evidence relevant to the question of sex- and gender-related biological plasticity and variation over developmental time among women.

${ }^{8}$ Epigenetics may also serve as a daguerreotype or biomarker confirming past or present hormonal activity at a particular well studied genomic site. 